100 years after the Constitution from Weimar what do we have left? The controversial heritage of Carl Schmitt

\title{
A 100 años de la Constitución de Weimar ¿qué nos queda?
}

La herencia polémica de Carl Schmitt

Guillermo Andrés Duque Silva

Universidad Rey Juan Carlos fielalatierra@hotmail.com

Cristina Del Prado Higuera

Universidad Rey Juan Carlos cristina.delprado@urjc.es

DOI: https://doi.org/10.15366/bp2019.22.014

Bajo Palabra. II Época. № 22. Pgs: 271-290 
Recibido: 03/12/2018

Aprobado: 02/10/2019

\section{Resumen}

Pocos periodos de la historia moderna resultan tan convulsionados y decisivos como la República de Weimar. Más allá de una crisis particular de la historia alemana, las vicisitudes políticas de Weimar configuran un "nudo gordiano" en el que se entrelazan hilos ideológicos que, de forma intermitente, se mantienen en pugna hasta el presente. En este artículo se examina el aporte del padre del decisionismo contemporáneo: Carl Schmitt. En el artículo se analiza la riqueza de la herencia schmittiana y su vigencia en el siglo XXI.

Palabras clave: Carl Schmitt, Alemania, Liberalismo, Constitución, Weimar.

\section{Abstract}

Few moments in modern age are as convulsive and decisive like the Weimar Republic. Beyond a particular crisis in German history, the political vicissitudes of Weimar Republic make up a "Gordian knot" in which ideological threads are woven together that, intermittently, they remain valid. In this paper we examine the contribution of the main representative of contemporary decisionism: Carl Schmitt. The document analyzes the richness of the Schmittian heritage and its validity in the 21 st century.

Keywords: Carl Schmitt, Germany, Liberalism, Constitution, Weimar. 


\section{Introducción}

El i I DE AGOSto De i9I9 entró en vigor la Constitución de la República de Weimar, desde ese momento hasta la elección de Hitler en 1933, la discusión académica sobre el futuro constitucional de Alemania será la obsesión de un buen número de juristas. Aunque los debates entre Hans Kelsen, Hermann Heller y Max Adler coparon los espacios de la prensa, finalmente pasaron a la historia y, salvo la lectura positivista en algún sentido, hoy es difícil afirmar la vigencia plena de sus planteamientos. Cien años después, lo contrario sucede con el filósofo del Derecho al que en el debate calificaba como "enemigo del Estado liberal"; el jurista Carl Schmitt. Su realismo político cada vez despierta más interés y sus postulados antipositivistas sobre lo político y el Derecho, cobran mayor vigencia.

No es un dato aislado que unos sesenta libros de Carl Schmitt se contaran en 1985, año de su muerte, y que hoy las publicaciones del autor superen el centenar, sin contar con las múltiples traducciones que incluyen, entre otros idiomas, el mandarín y el japonés. Filósofos de la talla de Jürgen Habermas, Giorgio Agamben, Alien Badiou y Slavoj Zizek han escrito y reflexionado sobre la vigencia de Schmitt y sus apreciaciones sobre el estado de excepción y el conflicto amigo-enemigo en la política. En este artículo se presenta una descripción comprensiva del pensamiento de Carl Schmitt en la República de Weimar. Se destaca el modo en que la coyuntura histórica, vital y nacional, impulsó sus planteamientos. La idea defendida en el texto es que existe una conexión complementaria entre dos etapas del pensamiento de Schmitt en Weimar, que corresponden metafóricamente con la figura del dios bifronte Jano, a quien sus dos cabezas le permitían ver el origen y el final de las cosas; lo que representa en Carl Schmitt su Teología politica de 1922 y su Concepto de lo político de 1927, respectivamente.

\section{Carl Schmitt. Filósofo del (y en el) conflicto}

Carl Schmitt pasará a la historia como a él más le gustaba definirse; como un jurista. Tuvo una personalidad compleja, sobre él se han vertido a lo largo de décadas multitud de opiniones, ideas... para Raymond Aron "pertenece a la escuela de 
los sabios alemanes que van más allá de su especialidad, que abarcan todos los problemas de la sociedad y de la política y a los que se puede llamar filósofos" ${ }^{1}$, otros politólogos piensan que su obra y pensamiento están llenos de contradicciones, posiblemente porque vivió en uno de los momentos más convulsos de la historia del viejo continente, captando como pocos el pathos de una época extraordinariamente movediza, cambiante y tensa, gravemente contradictoria en sí misma en los hechos y en las ideas, intelectualmente difusa y confusa, pero fascinante. Fue un testigo directo de la vida entre dos siglos, dos guerras mundiales y dos derrotas. Un gran humanista que supo bucear en la profundidad de la historia y de la cultura enfrentándose a una Europa desgarrada espiritual y políticamente.

Algunos autores como Raúl Morodo también definen a Schmitt como una de las inteligencias más lúcidas e ingeniosas, polémicas y destructoras de la cultura jurídica y política contemporánea, para Elías Díaz era el más inteligente interprete de la crítica fascista al Estado de derecho, una de cuyas características es la de repetir parcial, miméticamente y con grandes dosis de oportunismo e incoherencia algunos de los argumentos de la izquierda. Las tesis sobre Schmitt suelen ser contradictorias, para Estévez Araujo es un implacable sofista, mientras que Manuel Aragón define sus tesis como un "desafío para el pensamiento liberal y democrático" ${ }^{2}$. Por un lado, autores como Yves Zarka, lo catalogan como uno de los máximos responsables de la llegada de Hitler al poder, en palabras de Javier Esparza fue casi un monstruo en una etapa de la historia y por otro lado, Silva-Herzog le otorga el calificativo de "último gran clásico de la filosofía política" 3.

Visto su pensamiento con distancia podemos afirmar que no se acercó al poder como un ideólogo o como un político sino como un observador que quiso influir en el devenir de los acontecimientos sin codiciarlos, entendidos como una magnitud objetiva con leyes propias frente a cualquier individuo que pueda sustentarlos. Schmitt fue un intelectual ambicioso, como escribe Bendersky trató de compensar sus orígenes humildes, provenía de una clase media poco acomodada, mediante sus éxitos académicos. No podemos olvidar que nació en el seno de una familia católica aunque vivía en una zona de predominio protestante, de modo que, como subraya Schwab, fue muy consciente de la controversia del Kulturkampf, a pesar de su formación católica, no mantuvo la tradición escolástica del Derecho Natural, que, como indica Schwab, chocaba con su pensamiento apegado a situaciones históricas concretas. No buscaba tanto conseguir un estatus económico como el reconocimiento científico

${ }^{1}$ Raymond, A. Memorias, Madrid, Alianza editorial, 1985, p. 626.

2 Cfr.: Aragón M. "Estudio preliminar" En: Schmitt, C. Los fundamentos históricos-espirituales del parlamentarismo en su situación actual. Madrid, Tecnos, 1996, p. XI.

3 Silva-Herzog M. La idiotez de lo perfecto. Miradas a la política. México, FCE, 2006, pp. 19-21. 
y profesional, se le puede considerar un hombre poliédrico, vanidoso, él sabía que sabía y que contaba con sobrados recursos para demostrarlo, virtudes o defectos que le ayudaron a sobrevivir el contexto social y económico de la Alemania que le tocó vivir. Se definió a sí mismo como un hombre contemplativo, sosegado, silencioso y transigente, más bien defensivo. "Si como profesor 'gusta de formulaciones precisas', se encuentra con la ambigüedad e inseguridad por todas partes, mi caso 'es desagradable, poco glorioso y, sin embargo, auténtico de un Epimeteo cristiano' dirá Schmitt" ${ }^{4}$.

Tuvo una exquisita formación humanista, filosófica, histórica, sociológica y jurídica, que siempre aprovechó y utilizó con dialéctica sorprendente, incisivo en la crítica al liberalismo y en la exposición de sus puntos de vista. Sus fuentes fueron los grandes maestros clásicos Maquiavelo, Bodino, Hobbes, Tocqueville, Donoso Cortés... bebió de sus conceptos, pensamientos y obras, interpretando y acercándose a sus ideas con una sutil agudeza, un lector infatigable de la literatura francesa, espańola e italiana.

Perteneció a la gran generación de politólogos como Rudolfd Smend y Hermann Heller quienes renovaron la ciencia jurídica intentando entender una realidad más compleja que la del siglo XIX, poniendo de manifiesto que el problema fundamental del poder y la política era la crisis del Estado burgués de Derecho, enfrentándose a él. Sus armas teóricas fueron estudios detallados sobre la situación crítica y la realidad constitucional en la Europa del pasado siglo, analizó conceptos como la legalidad, el parlamentarismo, la dictadura y deslindó al soberano como aquel poder que decide en el estado de excepción. Sin encontrar eco para las que serían sus propuestas de solución a los grandes problemas en el orden político de Alemania, fue testigo del hundimiento del orden monárquico del Estado; de una economía sobrecogida por la inflación; las revueltas en la calle; la aniquilación; la guerra y el ascenso de Hitler. Tuvo que sobrevivir a los grandes interrogatorios contra el nazismo, vio como destruían su casa y su biblioteca; le usurparon lo que más amaba: su cátedra y con ella su forma de ganarse la vida.

Se ubicó en contra de las ideas de la República de Weimar de 1919, ya que para él, la nueva Constitución se situaba en la tradición francesa de 1789 y 1848 y del pensamiento socialista moderado, al que cuestionó decididamente. Fue un claro defensor del sistema presidencialista que se construirá sobre una deformación del sistema weimariano. Helmut Quaritsch ha definido su pensamiento en tres niveles, como católico, como estatista y como nacionalista, afirmando que no entierra Weimar, que no fue un precursor del nazismo, ni un agitador político, para él lo más importante era el Estado alemán, mientras que la Constitución en sentido

\footnotetext{
${ }^{4}$ Iribarne, M. F. "Carl Schmitt: el hombre y la obra”. Revista de estudios políticos, No. 122, Madrid, Instituto de Estudios Políticos, 1962, p.7.
} 
positivo tenía un carácter secundario. Schmitt ve en la República de Weimar una oportunidad perdida y en su Constitución una falta de esencia política; un cúmulo de contradicciones que en sólo unos meses fue capaz de llevar a Alemania al desastre. Mantuvo una actitud crítica sobre ella aun siendo consejero del canciller Von Schleicher, el último canciller de la República antes de Hitler, toda una serie de acontecimientos se precipitaron dando lugar a la victoria del nacionalsocialismo, a partir de este momento la figura de Schmitt es denostada por todas las fuerzas políticas comenzando para él un auténtico calvario personal. Algunos historiadores y filósofos de la política se han preguntado que aportó Schmitt a la República de Weimar, siendo uno de los actores más destacados del ordenamiento constitucional de ese periodo. Schmitt puso de manifiesto los problemas por los que atravesaba el Estado alemán del período de entreguerras y los gravísimos errores que encerraba el régimen parlamentario; se convirtió en su crítico más peligroso y a la vez el pensamiento de Schmitt no se explica sin él. Una de sus ideas más controvertidas es la crítica al parlamentarismo como forma de gobierno y de Estado, considerándole como la causa de la inestabilidad de los gobiernos. Otra es la noción de poder constituyente, como la fuerza capaz de ordenar jurídicamente a los Estados, sin necesidad de una justificación jurídica.

No podemos entender su pensamiento sin apuntar aunque sea de forma muy somera la influencia que tuvieron sobre Schmitt dos grandes países mediterráneos como Italia y Espańa, en estos dos países su pensamiento encontró un auténtico eco entre los intelectuales y políticos. En España tuvo una gran influencia en intelectuales de la talla de Álvaro D’Ors, Fernández de la Mora, Manuel Fraga, Tierno Galván...pero también su reflexión se alimenta de pensadores como Baltasar de Ayala o Francisco de Vitoria o Donoso Cortés. Consiguiendo lo que no había alcanzado en Alemania, ser un pensador de referencia tanto para políticos de izquierdas como de derechas, en algún momento llegó a reconocer que se sentía mejor comprendido en España que en su patria; incluso mejor malinterpretado. ${ }^{5}$

\section{La primera cara de Jano: El origen de la política según Schmitt}

Luego De una eTAPA QUe el mismo Schmitt califica como intuituva, en la que escribe sus primeros textos (1910-1918), el autor desarrolla un conjunto de análisis

\footnotetext{
5 Dominaba el castellano en el que se sentía muy cómodo tanto hablando como escribiendo, eran frecuente sus encuentros en universidades como la de Madrid, Barcelona, Granada, Zaragoza y muy especialmente en la de Santiago de Compostela ya que su hija Ánima vivía en esta ciudad en la que pasó largas temporadas. Casi toda su obra está traducida al castellano y algunos trabajos, gracias a su hija, se publicaron primero en Espańa.
} 
surigidos del balance de su propia experiencia vital en la Primera Guerra Mundial y el descontento que le genera la Constitución de la República de Weimar. Ambas fuentes de reflexión le conducen a un mismo lugar; el desarrollo de una teoría del estado de excepción. Por un lado, en la entrevista de Fulco Lanchester "Un jurista frente a si mismo" recientemente traducida al castellano, Schmitt explica que su teoría sobre el estado de excepción tuvo su origen en la Primera Guerra Mundial, a partir de su experiencia como "jefe de negociado en la oficina del estado de sitio que durante cuatro años gobierna la Alta Baviera [...] Déjeme que le explique" ${ }^{6}$, dice Schmitt:

"Mi teoría sobre el estado de excepción tiene su origen en la Primera Guerra Mundial. Yo fui oficial durante aquél conflicto y en 1915 sufrí un grave accidente, por lo cual, consecuentemente, me asignaron por tres años al Cuartel General Bávaro en Múnich.

[...] En aquella ocasión me asignaron a la Oficina P [Abteilung P], que se ocupaba de los problemas de la prensa, la política y la policía. Allí fui funcionario adscrito al estado de sitio; los bávaros en aquél período tenían un propio derecho para el estado de excepción. El estado de excepción prusiano se extendía por toda Alemania; mientras que los bávaros tenían uno de tipo particular. He sido jefe de negociado en la oficina del estado de sitio que durante cuatro años gobierna la Alta Baviera"7.

Por otro lado está la aversión que le genera el Artículo 48 de la Constitución de 1918, el cual se consagra el estado de excepción aplicable a la República de Weimar, el mismo refiere que:

"En el caso de un Estado que no cumpla con los deberes que le haya impuesto el Reich, la Constitución o las leyes del Reich, el presidente del Reich podrá hacer uso de las fuerzas armadas para compelerlo a hacerlo. Si la seguridad y el orden público al interior del Reich son severamente dañados o están en peligro, el presidente del Reich podrá tomar las medidas necesarias que lleven a restablecer el orden, interviniendo con la asistencia de las fuerzas armadas, de ser necesario. Para este propósito, podrá suspender temporalmente, totalmente o en parte, los derechos fundamentales (...). El presidente del Reich debe informar al Reichstag sin demora sobre todas las medidas tomadas de acuerdo a los párrafos $1 \mathrm{y}$ 2 de este artículo. Estas medidas pueden ser revocadas a petición del Reichstag. Si el peligro es inminente, el Gobierno del Estado puede tomar medidas temporales para su propio territorio, como lo provee el párrafo 2. Estas medidas pueden ser revocadas a petición del Reichstag. Los detalles serán determinados por una ley del Reich.” ${ }^{8}$

\footnotetext{
${ }^{6}$ Pérez, C. (trad.). "Carl Schmitt: Un jurista frente a sí mismo. Entrevista de Fulco Lanchester a Carl Schmitt”. Revista Carl-Schmitt-Studien, Berlín, CSS, 2017, p. 218.

7 Ibíd., p. 218.

${ }^{8}$ Buhler O. La Constitución de Weimar (texto de la constitución alemana de 11 de agosto de 1919), Madrid, Tecnos, 2010 p. 52.
} 
Es decir que Schmitt, quien combina la experiencia vivida del estado de sitio en el contexto de una guerra mundial perdida para Alemania, con la aversión teórica al parlamentarismo totalizante, consagrado en el Artículo 48 de la Constitución, figura a un soberano capaz de declarar un Estado de sitio, con las manos atadas y de rodillas al Reichstag (parlamento) que en últimas, gobierna sobre las decisiones del presidente del Reich. El resultado de la crítica de Schmitt, además de otros textos de inigualable pertinencia, será una obra con un calado filosófico profundo, al que titula Teología politica. Podemos iniciar afirmando que ese texto escrito en 1922 es la materialización del esfuerzo de Schmitt, por constituir una teoría política no liberal de la Modernidad. El centro de la argumentación de Schmitt es el concepto de decisión en y sobre el estado de excepción. Antes de abordar el poder constituyente que el autor otorga a la decisión "milagrosa" que suspende la ley y al mismo tiempo crea un nuevo Derecho, habría que empezar a explicar su poderosa sentencia: "Todos los conceptos centrales de la moderna teoría del Estado son conceptos teológicos secularizados." "Esta afirmación implica que el paso de la tradición a la modernidad trae consigo un desplazamiento de la figura de la trascendencia sagrada como fuente última de legitimidad del orden, pero revela al mismo tiempo su necesidad.

Según Schmitt, la idea de concepto teológico secularizado implica que si Dios, como fuente central incondicionada de poder, desaparece, al hacerlo, deja libre su lugar como deidad absoluta, para que el mismo sea ocupado por una instancia terrenal. "[Si] el Dios de la tradición ha sido destronado, no ha sido destruido el lugar que éste ocupaba en la organización de la estructura social.” ${ }^{10} \mathrm{El}$ ejercicio del gobierno, por su cuenta, sigue siendo una necesidad que opera en forma teológica, aún cuando sustancialmente la secularización de la política implique una ruptura con la tradición. Dicho "lugar de gobierno" según Schmitt es la soberanía, de tal manera que existe en su argumento una correspondencia entre el concepto de soberano y la noción de Dios trascendente ${ }^{11}$. En ese sentido, Teología política es una manifestación de la importancia que para Schmitt tiene el retorno al concepto de soberanía en una Edad en que conceptos como Dios, milagro y redención pasan de la trascendencia a la inmanencia secularizándose a la manera de poder, excepción y revolución, suponiendo al mismo tiempo ruptura de sustancia y continuidad de forma. La crítica de Schmitt al Reichstag, se basa en una definición de soberanía que

9 Schmitt, C. Teología política, Madrid, Trotta, 2009, p. 37.

${ }^{10}$ Ibíd., 37.

${ }^{11}$ Desde esta perspectiva, la teología política sólo se hace comprensible si se piensa que existe una discontinuidad en el nivel de la sustancia (Dios ya no funciona como fuente última de garantía del orden, el orden no está dado, debe ser creado por la voluntad y el artificio humano) pero a la vez, una continuidad en el nivel de la forma. 
supone que "el soberano es quien decide sobre el estado de excepción," 12 entendiendo el concepto de estado de excepción como una noción límite. ${ }^{13}$ Para Schmitt, la ponderación sobre la situación excepcional solamente puede ser realizada por el Soberano, de hecho sólo es del Soberano en tanto que decide acerca del estado de excepción. La decisión sobre el caso extremo, "límite", abre el tiempo del sujeto de la soberanía o, en términos de Schmitt, "cobra actualidad la pregunta acerca del sujeto de la soberanía, o sea sobre la soberanía en sí." ${ }^{14}$ El filósofo alemán nos propone una explicación del surgimiento y actualización del Estado de derecho en los hechos que se ubican por fuera del Derecho mismo. El momento exacto en que surge el Derecho, es el momento de la decisión sobre lo excepcional, luego, la decisión sobre la situación excepcional se convierte en la puerta de acceso al concepto de Soberanía y el concepto de Derecho: nada más distante del curso parlamentario. Desde el decisionismo schmittiano, el poder soberano recae sólo en quien decide desde afuera del ordenamiento jurídico, para suspenderlo y lograr condiciones de normalidad que permitan el desarrollo de la legalidad, por eso la posibilidad legal de dar marcha atrás a la decisión, que otorgaba la Constitución de Weimar al Reichstag, era para Schmitt ilegítima. No en vano pensadores contemporáneos, como Jesús Silva-Herzog, llaman a la propuesta de Schmitt una "ciencia de la ilegalidad", es decir, una apuesta teórica que rescata lo que se encuentra por fuera de la Ley y el Estado, para plantear una posible respuesta a la pregunta sobre el origen, precisamente, de la Ley y los Estados. Con la elección de este camino, Schmitt busca poner en evidencia, "la idiotez que se esconde tras la defensa de Estados liberales de Derecho como productos de la perfección y de la normalidad". ${ }^{15}$ Esto se explicita cuando Carl Schmitt nos recuerda la imprevisibilidad jurídica de la excepción y todo lo que ello implica:

"La tendencia del Estado de derecho a regular lo más a fondo posible el Estado de excepción no entraña sino el intento de circunscribir con precisión los casos en que el derecho se suspende a sí mismo. ¿Dónde toma el derecho esa virtud y cómo es posible lógicamente que una norma tenga validez excepto en un caso concreto que ella misma no puede prever de hecho?"16

\footnotetext{
12 Schmitt, C., op. cit., p. 13.

${ }^{13}$ La idea de limite implica dos condiciones: primero, implica la remisión a una situación fáctica de "extremus necessitatis casus" producto de una extrema necesidad histórica y material; segundo, que no se corresponde con principios instituidos en el Derecho Público como "estado de sitio", "ley marcial", "estado de necesidad" de "conmoción interior" o demás creaciones que dan cuenta de una situación extrema prevista por el legislador. Torres, F. "Carl Schmitt y Giorgio Agamben. Aventuras y desventuras de la excepción”. Congreso de Derecho Público para estudiantes y jóvenes graduados: Democracia y Derechos, Argentina, Universidad de Buenos Aires, 2009.

${ }_{14}$ Orestes H., Carl Schmitt, Teólogo de la Política, México, FCE, 2001, p. 25.

15 Silva-Herzog, M., op. cit., p. 25.

16 Schmitt, C., op. cit., p. 26.
} 
Para Schmitt, "la decisión sobre lo excepcional es la decisión por antonomasia." ${ }^{17}$ Ningún precepto o norma del Derecho puede anticipar la excepción absoluta. Tampoco puede decidir la normatividad por sí sola si algo puede ser calificado de excepcional o amerita la excepcionalidad extrema. Es decir, no es posible que lo propio del Estado de excepción sea contenido jurídicamente; ya que si quien decide es realmente soberano, su poder de decisión no puede estar controlado por otro, llámese Ley o unidad política alterna, ni dividir su facultad de decidir, por ejemplo en un parlamento. "El soberano decide si el caso propuesto es o no de necesidad y qué conviene hacer para dominar la situación. Cae, pues, fuera del orden jurídico normalmente vigente, sin dejar por ello de pertenecer a él, puesto que tiene competencia para decidir, por ejemplo, si la Constitución puede ser suspendida in totum." ${ }^{18}$

Enseguida se presenta un interrogante fundamental al planteamiento que ha sostenido Schmitt, en lo concerniente al soberano, éste ¿̨se encuentra siempre por encima o fuera de toda Ley y Derecho o se sale de él para decidir sobre la situación excepcional? Para afrontar este cuestionamiento el autor recurre al intelectual francés Jean Bodino, quien además de despertarle especial fascinación, le permite describir que la soberanía más que un Derecho, designa un poder. En Bodino la soberanía es el "poder absoluto y perpetuo de una República" ${ }^{19}$ y soberano es quien tiene el poder de decisión; esto es, dar origen a la ley y a las leyes sin recibirlas de otro. Siguiendo a Bodino, pero realizando un correcto desplazamiento a Hobbes, Schmitt afirma que si bien Bodino explicita la relación que tiene el concepto de "soberanía" con el de "necesidad" y con el de "decisión", la ley derivada de la soberanía no es sino la misma ley natural, distinta a la ley civil, sino que como sucede en Hobbes en el Capítulo XXVI del Leviatán, la ley civil y ley natural "no son especies diferentes, sino partes distintas de la ley; de ellas, una parte es escrita, y se llama civil; la otra no escrita, y se denomina natural" ${ }^{20}$. En consecuencia, Carl Schmitt, inspirado tanto en Bodino como en Hobbes, explica que la ley civil es producto del ejercicio soberano de decidir; por tanto todo orden descansa, en última instancia, en una decisión. Aún el orden jurídico se debe no a una norma, sino a una decisión. La pregunta subsiguiente sería ¿y quién decide en su soberanía? La aproximación a una respuesta la encuentra Schmitt, en gran medida inspirado en los argumentos maquiavélicos, en la descripción de un gobernante capaz de personificar la salvaguardia de la Constitución y el Estado. Es decir aquel que, como última instancia, "es competente cuando el orden jurídico no resuelve el problema

\footnotetext{
17 Ibíd., p. 15.

${ }_{18}$ Ibíd., p. 17.

19 Bodino, J., Los seis libros de la República, Madrid, Tecnos, 2005, p. 85.

${ }^{20}$ Hobbes, T., Leviatán, Madrid, Alianza Editorial, 1989, p. 225.
} 
de la competencia." ${ }^{21}$ El "príncipe" contemporáneo que ve Schmitt en la Alemania de la República de Weimar es un "príncipe con las manos atadas" que no puede, por causa del Artículo 48 de esa Constitución, decidir en última instancia sobre el Estado de excepción. El lugar providencial del soberano es ocupado en cuanto éste es competente para decidir sobre el Estado de excepción; un concepto límite comprendido como la posibilidad de suspender el orden jurídico, si es que tal decisión llega a ser necesaria. "El Estado de excepción es a la política, lo que es el milagro para la teología; el momento de la soberanía. La existencia del Estado deja en este punto acreditada su superioridad sobre la validez de la norma jurídica. La 'decisión' se libera de todas las trabas normativas y se torna absoluta, en sentido propio. Ante un caso excepcional, el Estado suspende el Derecho por virtud del derecho a la propia conservación." 22 "No existe una [norma o falta] que fuera aplicable a un caos. Menester es que el orden sea restablecido, si el orden jurídico ha de tener sentido. Es necesario de todo punto implantar una situación normal, soberano es quien con carácter definitivo decide si la situación es, en efecto, normal. El Derecho es siempre 'Derecho de una situación determinada'. El soberano crea esa situación y la garantiza en su totalidad.” ${ }^{23}$ Él asume el monopolio de la última decisión.

En ese sentido la norma necesita de una situación de normalidad generada por aquél gesto decisivo, soberano en su excepcionalidad, pero normalizador. Por lo tanto, la situación excepcional que no puede ser precisada ni contenida en una norma, es un dato no formalizable de lo real, reflejo y efecto de un "plus" o exceso, "imposible de cristalizar en una norma jurídica." ${ }^{24}$ Según Schmitt, "la excepción, que precede lógica y gnoseológicamente a la norma, es el conflicto que, en cuanto contingencia insuperable, es inicio absoluto, origen de la forma político jurídica." ${ }^{25}$. "Vemos que en tal caso la decisión se separa de la norma jurídica y, si se nos permite la paradoja, la autoridad demuestra que para crear derecho no necesita tener derecho." 26

\section{La finalidad de la políticał la segunda cara de Jano en Carl Schmitt}

EN LA SEGUNDA MITAD DE LA DÉCADA DE SIGLO XX, la radicalización política de Schmitt se hace más evidente. El ambiente inestable de una Alemania asediada por la crisis

\footnotetext{
21 Schmitt, C., op. cit., p. 22.

22 Schmitt, C., Politische Theologie, 1922, 2.a edición 1934, reedición. Berlín, Duncker und Humblot, 2004, p. 46.

${ }_{23}$ Schmitt, C., Teología politica, Madrid, Trotta, 2009, p. 25.

24 Torres, F., op. cit., p 45.

25 Schmitt, C., op cit., p. 70.

${ }^{26}$ Ibíd., p. 25.
} 
económica, "una posible invasión soviética y el crecimiento paulatino del movimiento nacionalsocialista, reflejaba una preocupación especial en Schmitt." ${ }^{27}$ Schmitt anhela la transformación institucional y el fin de la República de Weimar. Confía en que la crisis generará una "re-fundación" del Estado alemán por fuerza del antagonismo social y religioso entre el liberalismo político y el conservatismo revolucionario. Ese anhelado estado de excepción, se ve usurpado, además, por el Artículo 76 de la Constitución de Weimar, a través del cual se consagraba que el parlamento, con una mayoría suficiente, quedaba facultado para reformar la Constitución y cambiar, si lo veía necesario, la identidad y principos del Estado, "convirtiendo una república en una monarquía, un Estado federal en uno centralizado, un Estado con derechos fundamentales, en uno sin esos derechos," ${ }^{28}$ si así lo quería. Con ello se neutralizaba a su paso, todo intento extra-parlamentario de suspensión de la Constitución. Para Schmitt, esa "dictadura parlamentaria", constituía la degeneración más radical de una versión de la democracia que se encierra a sí misma en un contrasentido; "toda reforma que impactara en la identidad de la Constitución, anula la legalidad y legitimidad de dicha Constitución" ${ }^{29}$ a la que no se le debería en adelante, respeto por status soberano alguno.

En ese contexto, el parlamento había copado todos los espacios de la acción política, lo político quedaba reducido al procedimiento parlamentario y no podía concebirse por fuera de él. Frente a ello, la oposición intelectual de Schmitt se fortifica en la defensa de la idea de Constitución como poder vinculante, en una resumida definición conservadora y revolucionaria de la esencia o concepto de lo político. En el ensayo del mismo nombre, Carl Schmitt pone en evidencia las múltiples contradicciones de las democracias liberales. La que aquí se desea abordar, como emblemática en su segunda etapa en Weimar, consiste en la denuncia a la pespectiva liberal que suele adscribir lo político al monopolio de lo estatal y que explica las relaciones políticas, únicamente, como algo que sucede gracias a y dentro del Estado. Para Schmitt, el enfoque liberal burgués ignora que, "aunque lo político en algunos momentos de la historia ha sido parte de los marcos del Estado, éste puede sobrevivir fuera de él," 30 en terrenos que se presentan "neutrales" a los ojos del liberalismo, como la educación, la economía, la religión y la cultura. En dichos ámbitos, puede emerger en todo momento lo político como conflicto, de forma independiente a los marcos estatales. La perspectiva liberal asume que lo político

\footnotetext{
${ }_{27}$ Duque, G., "Rueda suelta entre los nazis: la aversión teórica de Carl Schmitt frente al nazismo". Revista Prolegómenos Derechos y Valores, 19, 37, Colombia, Universidad Militar Nueva Granada, 2016, p. 95.

${ }_{28}$ Schlink, B., “¡Por qué Carl Schmitt?”. Revista Precedente jurídico, No. 20, Colombia, Universidad ICESI, 1997, p. 38 .

29 Duque, G., op. cit., p. 92.

${ }^{30}$ Delgado M., "El criterio amigo-enemigo en Carl Schmitt: El concepto de lo político como una noción ubicua y desterritorializada”. Revista Cuaderno de Materiales, No 4, Vol. 1, México, Ed. UNAM, 2001, p. 30.
} 
y lo estatal corresponden en sus mismos límites, en lugar de reconocer, como lo indica Schmitt, que primero existe lo político y que de él surge, en una segunda instancia, el Estado. La primera enseñanza de Schmitt, en esta obra, consiste en que el "concepto del Estado presupone el concepto de lo político" 31 y que lo político no se reduce a lo Estatal, sus procedimientos y estructura jurídica, sino que sucede lo contrario; lo político es la condición previa y necesaria para la existencia misma del Estado y del Derecho. Esta definición de lo político no podía ir más en contra a lo planteado en la Constitución de 1918. Lo político para Schmitt remite a la noción de poder constituyente; a una preeminencia del poder sobre el Derecho constituído y las formas jurídicas del Estado, incluyendo el parlamento.

En El concepto de lo politco, Schmitt cita a Albert Haenel para afirmar que "es un error manifiesto generalizar el concepto del Estado para convertirlo en el concepto por excelencia de la sociedad humana" ${ }^{32}$. Schmitt coincide con Haenel, quien califica expresamente como incorrecta la opinión según la cual, el Estado tendría, al menos potencialmente, como objetivo; todos los objetivos sociales de la humanidad. Al contrario, el Estado, aun siendo universal, de ningún modo es total, ${ }^{33}$ es una unidad histórica, contaminada por un contexto, con un principio y un final. Si el Estado presupone lo político, entonces ¿qué es lo político? Según Schmitt, para constatar un concepto de lo político habría que definir las categorías estrictamente políticas que servirían de criterio para la distinción de un ejercicio político frente a una actividad de otro tipo, por ejemplo moral, económica y estética. Schmitt propone una distinción mínima sobre la cual adquieren sentido político las acciones humanas. Nos dice que: "la distinción política específica, aquella a la que pueden reconducirse todas las acciones y motivos políticos, es la distinción de amigo y enemigo." ${ }^{34}$

Supongamos que, en el área de lo moral las diferenciaciones últimas están dadas por el bien y el mal; que en lo estético lo están por la belleza y la fealdad; que lo estén por lo útil y lo perjudicial en lo económico o bien, por ejemplo, por lo rentable y lo no-rentable. La cuestión que se plantea a partir de aquí es la de si hay - y si la hay, en qué consiste - una diferenciación especial, autónoma y por ello explícita sin más y por si misma, que constituya un sencillo criterio de lo político y que no sea de la misma especie que las diferenciaciones anteriores ni análoga a ellas. ${ }^{35}$

\footnotetext{
31 Schmitt, C., El Concepto de lo Político, Madrid, Alianza editorial, 1991, p. 11.

32 Ibíd., p. 32.

33 La doctrina estatal alemana (bajo la influencia dejada por el sistema filosófico-estatal de Hegel), continuó afirmando que el Estado, frente a la sociedad, sería algo cualitativamente diferente y superior (Schmitt, C., op cit., p. 32).

34 Ibíd., p. 32.

35 Ibíd., p. 12.
} 
La diferenciación amigo-enemigo es, en sí misma, una definición conceptual, un criterio más que una expresión o definición exhaustiva de contenidos. La objetividad y autonomía de este criterio frente a otros, le otorga la consistencia propia de una definición ontológica de lo político. En este sentido, el concepto de lo político deviene dinámico pues sugiere un nivel de decisión en el actor, al obligarle a definir su lugar en la dicotomía amigo-enemigo. Tal decisión se constata en dos niveles: por un lado, es "constitutiva, porque su nueva forma exige la configuración infinita de los pueblos alrededor de una identidad -en la esfera pública- para oponerse y construirse frente a otros pueblos" ${ }^{36}$; y, polémica, por otro lado, "porque en ella se establece una agrupación, dentro y fuera de las arenas estatales, con vistas a un antagonismo concreto entre amigos y enemigos que se manifiesta en una relación de hostilidad." ${ }^{37}$ Entonces, "la diferenciación entre amigos y enemigos tiene el sentido de expresar el máximo grado de intensidad de un vínculo o de una separación, una asociación o una disociación." ${ }^{38}$ Para Schmitt las contraposiciones amigo-enemigo, no son de orden jurídico, ni simbólico, sino reales. Se sustentan en la posibilidad concreta e histórica de un enfrentamiento público. En este punto es importante diferenciar al enemigo político de cualquier otra oposición que tenga lugar en el ámbito privado. Dicha capacidad de identificar al enemigo público y enfrentarle, es lo que permite distinguir a las unidades políticas de otro tipo de agrupación. Por ejemplo, una colectividad que en el Estado de derecho resulta apolítica como una comunidad religiosa; si libra guerras, "contra los miembros de otras comunidades religiosas, [entonces], es una unidad política más allá de constituir una comunidad religiosa [...] Toda agrupación es, en ese sentido, potencialmente política [...]. La posibilidad concreta de agrupamientos del tipo amigo-enemigo es suficiente para crear, por sobre lo puramente social asociativo, una unidad determinante." 39

En una situación de guerra, que es en todo caso una posibilidad real y el más alto grado de manifestación en la diferencia amigo-enemigo, no es posible explicar o justificar a partir de la normatividad -sin recurrir a la impugnación excepcional de un enemigo interno o externo- la exigencia que hace un Estado a sus "asociados" de matarse los unos a los otros. En realidad, afirma Schmitt "no existe ninguna relación jerárquica, ninguna legitimidad o legalidad razonables sin la correspondencia entre protección y obediencia. El protego ergo obligo es el cogito ergo sum del Estado y una teoría del Estado que no sea sistemáticamente consciente de esta frase perma-

\footnotetext{
6 Delgado, M., op. cit., p. 32.

37 Ibid., p. 36.

${ }^{38}$ Schmitt, C., op. cit. p. 15.

39 Schmitt, C., op. cit., pp. 21-24.
} 
necerá siendo un fragmento insuficiente. ${ }^{40}$ Dicha relación de protección-obediencia presupone la politización de un Estado que ha logrado identificar a un enemigo y con ello la identificación de un proyecto político que genera la pertenencia y la demanda de protección en la agrupación "amiga" «1 . De este modo, Schmitt borra toda presunción de imparcialidad, neutralidad o apoliticidad en el Estado.

Finalmente Schmitt argumenta que el discurso liberal ignora deliberadamente el conflicto para legitimarse, asumiendo como derrotero ideológico un rol estrictamente despolitizador. Efectivamente, finalizando el Concepto de lo político (1929, 1991) el alemán explica como el liberalismo traslada todo un sistema de conceptos "desmilitarizados" para darse sustento bajo el ocultamiento de los principios conflictuales dinamizadores de la vida política. Sobre este punto Schmitt afirma que los eufemismos liberales son empleados con frecuencia para encubrir la esencia bélica de lo político, y para vedar la práctica generalizada de enfrentamientos entre colectividades. A esto, el liberalismo le superpone denominaciones más cordiales con la lógica de la acción racional, y en una expresión distintivamente liberal, "le confiere un rostro diferente a cada concepto político." ${ }^{42}$ Por ejemplo, bajo condicionantes éticos y políticos el concepto de lucha es transformado por la primera determinante en discusión, y por otro lado, en competencia, el Estado se torna en sociedad de ciudadanos desde una perspectiva ética y por el lado económico-comercial; en un espacio-obstáculo para la libre producción y tráfico. Las voluntades propias de ejercer el ius belli al reconocer a nuestro enemigo e impugnarlo, se convierten en la construcción racional de un ideal o programa y en el sentido económico en una tendencia o en un cálculo económico. El pueblo se convierte, por un lado en público y por el otro en personal laboral y empresarial y en masa de consumidores etc. ${ }^{43}$ Así, para Schmitt la omnipotencia del Reichstag, consagrada en los Artículos 48 y 76 de la Constitución de Weimar, estaba lejos de ubicarse en la neutralidad y el desinterés que pregonaban, representaban en su lugar una orientación específicamente ideológica con un objetivo claro: despolitizar los conflictos sociales de un país devastado por la guerra y "contener" lo político en la celda parlamentaria. Para Schmitt la nueva República, era la materialización del sueño liberal, que buscaba convertir su doctrina económica imperial en una ideología política capaz de actuar bajo el disfraz neutral de la Constitución.

Tres años después de publicado El concepto de lo político empiezan los años treinta y el panorama político alemán no favorecía una lucha amigo-enemigo, entre el

\footnotetext{
${ }^{40}$ Ibíd., p. 31.

${ }^{41}$ Delgado, M., op. cit., p. 38.

42 Schmitt, C., op. cit., p. 26.

43 Ibid., p. 25.
} 
liberalismo parlamentario y el conservatismo revolucionario que deseaba Schmitt. El Movimiento Revolucionario Conservador Alemán al que pertenecía el autor, tendía a desaparecer con el ascenso del nazismo; ese "movimiento peligroso" que conduciría a Alemania al "fracaso del orden institucional." ${ }^{44}$ Intelectuales como Oswald Spengler, Moeller van den Bruck, Ludwig Klages, Ernst Niekisch, y el amigo de Schmitt; Ernst von Salomon Jünger, entre otros simpatizantes de la misma tradición conservadora, luego de la elección de Hitler, tuvieron que decidir entre huir de Alemania o asumir su nuevo contexto como una oportunidad para vivir en (y a pesar de) el III Reich. Al final frente a Schmitt, se posó la figura de un Hitler que no era culto, no era católico, ni conservador y sin embargo, estaba dispuesto a tomar decisiones frente a Weimar y eso, al padre del decisionismo... le bastó.

\section{Conclusión}

LAS DOS ETAPAS QUE COMPONEN EL ANÁLISIS de este artículo ofrecen potentes elementos críticos, vitales de la herencia schmittiana y fundamentales en la tarea de comprender el presente político. El primer Schmitt nos habla del origen de la política, el que ubica en la decisión sobre el Estado de excepción: un acto soberano que surge de la tensión entre el deber ser y la voluntad soberana y el segundo nos indica la finalidad de la política, en el instante en el cual esa tensión se cierra con el triunfo de una colectividad específica que logra constituir una adecuación particular, interesada y orientada a fines ideológicos concretos, entre el Derecho y el Poder. El Derecho, las Leyes y la Constitución, desde esa perspectiva, se entienden como instrumentos de dominación en constante adecuación y el Estado, como un "botín de guerra" en las luchas amigo-enemigo. Desde esa perspectiva la Constitución de Weimar, era entendida como la prenda de victoria que esgrimían los vencedores de la Primera Guerra Mundial; con su crítica a los Artículos 48 y 76, Schmitt desveló el interés ideológico liberal que se escondía tras el halo de neutralidad con que se presentaban las facultades excepcionales del Reichstag y la contención al poder ejecutivo del Presidente del Reich.

Estas coordenadas sobre el origen y la finalidad de lo político en Schmitt, aportan elementos interesantes a una comprensión del presente, si asumimos que occi-

\footnotetext{
${ }^{44}$ Schmitt, C., En: Balakrishnan, G., The enemy: an intellectual portrait of Carl Schmitt. Londres, Verso, 2000, p. 177. En 1976 dirá finalmente, que las divisiones religiosas jugaron un papel importante en el ascenso de Hitler, a quien le vino bien el sentimiento anticatólico [anti-römischer Affekt] de los alemanes. Dice Schmitt, que si Hitler hubiera sido católico, seguramente habría fracasado en su empresa electoral. La primera pregunta cuando apareció Hitler fue: ¿es católico o no? Si hubiese sido católico, hubiese sido un fracaso" Schmitt, en Pérez, C., op. cit., p. 221.
} 
dente es hoy un escenario construido con arquitectura schmittiana; un laboratorio vivo del Estado de excepción y de la primacía del Poder sobre el Derecho. Es imposible encontrar una justificación jurídica-liberal, por ejemplo, para la existencia del terrorismo, por un lado, o las "guerras prodemocráticas" antiterroristas, (pensemos en Siria, Irak, Afganistán,...), por otro lado. También es innegable que en la actualidad las posibilidades de reactivación de las luchas amigo-enemigo bajo nuevas formas (antagonismos religiosos, económicos, étnicos, nacionalistas que se tornan en antagonismos políticos) se mantienen presentes, de hecho se incrementan y llevan a nuevos estados de excepción y con ellos a nuevas adecuaciones del Derecho a través del Poder; un camino lejano del tradicional curso parlamentario. Tal vez por eso se ha despertado actualmente un interés generalizado en Carl Schmitt, incluso entre pensadores liberales. La cita recurrente a Schmitt entre liberales, hace notar una paradoja pues, si los liberales de hoy deben aprender "algo" de uno de los más distinguidos ideólogos de la oposición antiliberal es porque, seguramente, asistimos a la peor crisis que haya vivido el liberalismo político en su historia. En efecto, el interés por Carl Schmitt puede entenderse como un signo de la crisis liberal como poder hegemónico en el siglo XXI. En dicha crisis y al igual que en la República de Weimar, la obra de Schmitt ofrece un modelo alterno la liberalismo y el marxismo, que legitima el ejercicio del poder como una actividad permanente en el escenario político y que ubica a su acción constituyente antes de y por encima del derecho, la deliberación y el consenso. Podríamos decir, que el interés por Schmitt se debe, o al menos coincide, con una situación real: la experiencia histórica en primeros ańos del siglo XXI, como hace cien años en Alemania, parece desbordar con hechos las capacidades teóricas del liberalismo. Lo que venga de esta experiencia dependerá de nuestra capacidad de elección frente a una cuestión fundamental: pensar lo político por fuera de los límites del liberalismo y aceptar la herencia polémica de Schmitt, o insistir en mantener viva la democracia liberal por medios artificiales, como sucedió con la República de Weimar y con las consecuencias que ello implicó... la decisión. 


\section{Referencias Bibliográficas}

Balakrishnan, G., The enemy: an intellectual portrait of Carl Schmitt, Londres, Verso, 2000, pp. 740.

Bodino, J., Los seis libros de la República, Madrid, Tecnos, 2005, pp. 305.

Buhler O., La Constitución de Weimar, Madrid, Tecnos, 2010, pp. 376.

Delgado M., "El criterio amigo-enemigo en Carl Schmitt: El concepto de lo político como una noción ubicua y desterritorializada", Revista Cuaderno de Materiales, No 4, Vol. 1, México, Ed. UNAM, 2001, pp. 32-54 DOI: http://dx.doi. org/10.7440/res45.2013.11.

Duque, G., Rueda suelta entre los nazis: la aversión teórica de Carl Schmitt frente al nazismo. Revista Prolegómenos Derechos y Valores, 19, 37, Colombia, Universidad Militar Nueva Granada, 2016, pp. 85-98. DOI: http://dx.doi. org/10.18359/prole.1681

Hobbes, T., Leviatán. Madrid, Alianza Editorial. 1989, pp. 832.

Iribarne, M. F., "Carl Schmitt: el hombre y la obra”. Revista de estudios políticos, Número 122, Madrid, Instituto de Estudios Políticos, 1962, pp. 17.

Orestes H., (2001). Carl Schmitt, Teólogo de la Política, México, FCE, pp. 503.

Pérez, C., (trad.) "Carl Schmitt: Un jurista frente a sí mismo. Entrevista de Fulco Lanchester a Carl Schmitt". Revista Carl-Schmitt-Studien, Berlín. CSS, 2017, pp. 203-223 Disponible en: http://www.carl-schmitt-studien.de/index. $\mathrm{php} / \mathrm{schmitt/article/view/32/17}$

Raymond, A., Memorias, Madrid, Alianza editorial, 1985, pp. 740.

Schlink, B., “¿Por qué Carl Schmitt?” Revista Precedente jurídico, No. 20, Colombia, Universidad ICESI, 1997, pp. 37-53 DOI: https://doi.org/10.18046/ prec.v0.1415

Schmitt, C., El Concepto de lo Politico. Madrid, Alianza editorial, 1991, pp. 160.

Schmitt, C., Los fundamentos históricos-espirituales del parlamentarismo en su situación actual, Madrid, Tecnos, 1996, pp. 264.

Schmitt, C., Politische Theologie, 1922, 2. a edición 1934, reedición, Berlín, Duncker und Humblot, 2004. pp. 168.

Schmitt, C., Teología Politica. Madrid, Trotta, 2009, pp. 180. 
Silva- Herzog, M., La idiotez de lo perfecto. Miradas a la politica, México, FCE, 2006, pp. 187.

Torres, F., "Carl Schmitt y Giorgio Agamben. Aventuras y desventuras de la excepción". Congreso de Derecho Público para estudiantes y jóvenes graduados: Democracia y Derechos. Argentina, Universidad de Buenos Aires, 2009, pp. 9 Recuperado de: http://www.derecho.uba.ar/institucional/deinteres/teoria-del-estado-federico-torres.pdf

DOI: https://doi.org/10.15366/bp2019.22.014

Bajo Palabra. II Época. № 22. Pgs: 271-290 
